\title{
Responses of Sitophilus oryzae (Coleoptera: Curculionidae) and Tribolium confusum (Coleoptera: Tenebrionidae) to traps baited with pheromones and food volatiles
}

\author{
Christos G. ATHANASSiOU ${ }^{1}$, Nickolas G. KAVAllieratos ${ }^{2 *}$ and Pasquale TREMATERRA ${ }^{3}$
}

${ }^{1}$ Laboratory of Agricultural Zoology and Entomology, Agricultural University of Athens, 75 Iera Odos str., 11855 Athens, Attica, Greece

${ }^{2}$ Laboratory of Agricultural Entomology, Department of Entomology and Agricultural Zoology, Benaki Phytopathological Institute, 8 Stefanou Delta str., Kifissia, Attica, Greece; e-mail: nick_kaval@hotmail.com

${ }^{3}$ Department of Animal, Plant and Environmental Science, University of Molise, Via De Sanctis, 86100 Campobasso, Italy

Key words. Pheromone, food volatiles, traps, stored-product beetles, Sitophilus oryzae, Tribolium confusum

\begin{abstract}
The behavioural responses of two species of stored-product beetles, Sitophilus oryzae (L.) and Tribolium confusum Jacquelin du Val, to certain stimuli were studied in laboratory choice tests. The results of these experiments indicated that, with one species present, $S$. oryzae and $T$. confusum adults were equally attracted to traps baited with the aggregation pheromone of that species and to traps baited with both pheromones. In contrast, when both species were present, neither $S$. oryzae nor $T$. confusum showed specific behavioural trend towards a stimulus. Traps baited with $1 \mathrm{~g}$ of a mixture of plant extracts were significantly more attractive for both species than unbaited traps, but this response was highly influenced by the number of individuals of each species released. Traps baited with filter papers that were previously contaminated by live adults of both species were particularly attractive for $S$. oryzae, but not for $T$. confusum. Traps that contained 10 seeds damaged by $S$. oryzae were significantly more attractive than traps containing an oil lure or control traps for $S$. oryzae, but not for $T$. confusum. The addition of oil to the seeds did not affect the attractiveness of the trap for $S$. oryzae. Traps that contained 20 live $S$. oryzae adults were significantly more attractive than traps containing 20 dead $S$. oryzae adults or control traps. No significant differences were noted between traps containing 20 dead $S$. oryzae adults and control traps. The presence of S. oryzae adults in traps did not affect the response of T. confusum.
\end{abstract}

\section{INTRODUCTION}

Early detection of the presence of a pest is the basis of sampling storage facilities (Wilkin, 1990). Several studies demonstrate that trapping is more effective than absolute estimates because initial infestations can be detected earlier using traps than by direct sampling (Subramanyam \& Hagstrum, 1995; Hagstrum et al., 1998; Athanassiou \& Buchelos, 2001). There are several factors that determine the behavioural response of stored-product beetles to trapping devices or a given stimulus. These factors include characteristics of the insect, such as sex, age and mated state, or the type of attractant (food, pheromone, etc.). The feasibility of using these parameters when developing an Integrated Pest Management-based sampling plan has been extensively evaluated in the laboratory by many researchers (Cox et al., 1990; Phillips et al., 1993; Trematerra et al., 1996, 2000). In these tests, each species' response to a given attractant is examined separately, in single-species bioassays. However, field studies indicate that single-species infestations in storage facilities are rare and coexistence of several species is usual.

Apart from the factors mentioned above, it is likely that a given species' behavioural response to a given stimulus may be influenced by the presence of other species. Therefore, in cases of coexistence, trap catches may not be representative of actual densities, since a given species may not be detected in numbers that correspond to its density, due to interactions with other species that share the same resource. Apart from their response to specific attractants, individuals respond to volatiles derived from other individuals of the same or other species sharing the same niche (Trematerra et al., 1996, 2000; Phillips, 1997). However, there is still inadequate information on the affect of the outcome of interactions among species on their behaviour.

A succession of species is a key element in the establishment of an infestation in storage facilities (Rees, 1995). For instance, in stored grain primary pests can infest sound kernels and thus are the first colonizers of grain. Other species, the secondary pests, infest usually broken or damaged kernels; hence, it is likely that specific chemical signals from infested seeds or primary pests may stimulate them to infest suitable grain. Concomitantly, the increase in the density of secondary colonizers may stimulate primary pests to disperse and colonize undamaged grain.

In the present study the behavioural responses of two stored-grain beetle species to specific stimuli in the presence and absence of the other species were evaluated. The influence of volatiles from one species on the behaviour of the other species was also examined. The primary pest, the rice weevil, Sitophilus oryzae (L.) and the secondary

\footnotetext{
* Corresponding author.
} 
pest, the confused flour beetle, Tribolium confusum Jacquelin du Val were used. The results of the present study will help in the development of a protocol based on floor traps, which may be suitable for monitoring stored product pests.

\section{MATERIAL AND METHODS}

The adults of $S$. oryzae and T. confusum used in the tests were taken from cultures that were kept in the laboratory in whole wheat (for $S$. oryzae) and wheat flour plus $8 \%$ brewers yeast by weight (for $T$. confusum), at $26 \pm 1{ }^{\circ} \mathrm{C}, 70 \pm 5 \%$ r.h. and continuous darkness.

The tests were carried out in a cylindrical arena made of plexi-glass, $45 \mathrm{~cm}$ in diameter and $30 \mathrm{~cm}$ high. Teflon paint was applied to the upper internal part of the arena to prevent beetles from escaping. In this arena three modified Flit-Trak $\mathrm{M}^{2}$ traps (Trècè Inc, USA) were placed, and 100 beetles, of mixed sex and age were released at the centre of the arena, as suggested by Trematerra et al. (2000). The number of individuals trapped was checked $24 \mathrm{~h}$ after their introduction into the arena. All tests were conducted in incubators, set at $26 \pm 1^{\circ} \mathrm{C}, 70 \pm 5 \%$ r.h., and in continuous darkness. There were 6 experiments (series of tests) with six replicates of each test (see below).

\section{Experiment 1}

The first trap in the arena contained a lure loaded with $1 \mathrm{mg}$ of sitophilure, the aggregation pheromone of $S$. oryzae (Walgenbach et al., 1987; Levinson et al., 1990; Likhayo \& Hodges, 2000), the second a lure loaded with the aggregation pheromone of Tribolium spp. (Trècè Inc, USA), and the third with both pheromones. There were three series of tests: 100 S. oryzae; 100 T. confusum; $50 \mathrm{~S}$. oryzae $+50 \mathrm{~T}$. confusum adults were introduced into the arena in the first, second and third series, respectively. A previous three-choice test with three empty traps in the arena indicated that there were no significant differences in the capture efficiency among empty (control) traps $(P>0.05)$.

\section{Experiment 2}

The first trap contained $1 \mathrm{~g}$ of a multiattractant, which is a mixture of natural plant extracts such as carob extract in cellulose fibre pads (Agrisense BCS, UK), the second $2 \mathrm{~g}$ of the same substance and the third was empty (control trap). There were five series of tests using different ratios of the two species: $100 \mathrm{~S}$. oryzae; 100 T. confusum; $50 \mathrm{~S}$. oryzae +50 T. confusum; $80 \mathrm{~S}$. oryzae $+20 \mathrm{~T}$. confusum; $20 \mathrm{~S}$. oryzae $+80 \mathrm{~T}$. confusum adults in each series, respectively. A preliminary test indicated that there were no significant differences in the capture efficiency between empty traps and those containing filter paper $(P$ $>0.05)$.

\section{Experiment 3}

Two different types of filter paper $\left(4.5 \mathrm{~cm}^{2}\right.$ size, Indigo Instruments, Canada) presumed to be impregnated with the naturally occurring pheromones of $S$. oryzae and $T$. confusum: 5 $S$. oryzae $+5 T$. confusum adults were enclosed in the first; $50 \mathrm{~S}$. oryzae $+50 \mathrm{~T}$. confusum adults in the second. Twenty-four hours later, the insects were removed from the filter paper. In this test, the first trap contained the first paper, the second trap the second paper and the third was empty (control trap). There were three series of tests based on different numbers of beetles released: $50 \mathrm{~S}$. oryzae $+50 \mathrm{~T}$. confusum; $80 \mathrm{~S}$. oryzae $+20 \mathrm{~T}$. confusum; or $20 \mathrm{~S}$. oryzae $+80 \mathrm{~T}$. confusum in each series, respectively.

\section{Experiment 4}

The first trap contained an oil lure (Trècè Inc, USA; composition not available), the second 10 wheat seeds damaged by $S$. oryzae and the third was empty (control trap). There were two series of tests: $100 \mathrm{~S}$. oryzae or $100 \mathrm{~T}$. confusum adults were introduced into the arena, respectively.

\section{Experiment 5}

As in Experiment 4, but this time one of the traps contained the oil lure +10 wheat seeds damaged by $S$. oryzae, instead of oil alone. There were two series of tests: $100 \mathrm{~S}$. oryzae or $100 \mathrm{~T}$. confusum adults were introduced into the arena, respectively.

\section{Experiment 6}

The first trap contained 20 live, the second 20 dead S. oryzae adults, the third trap was empty and served as a control. There were two series of tests: $100 \mathrm{~S}$. oryzae or $100 \mathrm{~T}$. confusum adults were introduced into the arena, respectively.

Trap catches were expressed as percentage and transformed to normalize the results as suggested by Trematerra et al. (1996, 2000). The data were analysed using one-way Kruskal-Wallis Anova, separately for each experiment, using the statistical package JMP V.4 (Sall et al., 2001). For comparison of the means, Tukey's Multiple Comparison Difference was used at $P$ $=0.05$ (Siegel \& Castellan, 1988).

In all experiments lures and trap contents were renewed after each replication.

\section{RESULTS}

\section{Experiment 1 (Fig. 1A-D)}

When $100 \mathrm{~S}$. oryzae adults were released in the arena, significant differences were noted among the three traps (KW Anova, $\chi^{2}=10.34, P=0.0057$ ). Significantly more adults were found in the traps that were baited with the Sitophilus pheromone, with or without the Tribolium pheromone, compared to the traps that contained the Tribolium pheromone (Fig. 1A). Similarly, in the case of the 100 Tribolium release, significant differences were recorded among traps $\left(\mathrm{KW}\right.$ Anova, $\chi^{2}=8.87, P=$ 0.0118 ). Significantly more $T$. confusum adults were found in the traps that contained the Tribolium pheromone compared to those baited with the Sitophilus pheromone (Fig. 1B). When both species were introduced into the arena, no specific behavioural preference was manifested by $S$. oryzae (KW Anova, $\chi^{2}=2.34, P=0.3103$ ) or T. confusum (KW Anova, $\chi^{2}=0.35, P=0.8353$ ) (Fig. $1 C, D)$. Significantly more $T$. confusum adults were found in traps than $S$. oryzae when the two species were released together $\left(\chi^{2}=21.74, d f=1, P<0.0001\right)$ or separately $\left(\chi^{2}=23.41, d f=1, P<0.0001\right)$.

\section{Experiment 2 (Fig. 2A-H)}

When $S$. oryzae adults were introduced alone, significant differences were noted (KW Anova, $\chi^{2}=9.26, P=$ $0.0098)$. Significantly more weevils were found in the traps that contained the attractant, at both levels, compared to the control traps (Fig. 2A). The results were similar when only $T$. confusum was released (KW Anova, $\left.\chi^{2}=11.38, P=0.0034\right)$, but the catches in traps with $2 \mathrm{~g}$ of the attractant were not statistically different from that of the control traps (Fig. 2B). When 50 adults of each species were introduced into the arena, the behavioural 
responses of both species were similar (KW Anova, $\chi^{2}=$ 9.15, $P=0.0103$ for $S$. oryzae, $\chi^{2}=12.99, P=0.0015$ for T. confusum) (Fig. 2C, D); however, in this test, $S$. oryzae responded similarly to traps that contained $2 \mathrm{~g}$ of the attractant and control traps (Fig. 2C). When 80 S. oryzae were released with $20 \mathrm{~T}$. confusum the results were similar with previously (KW Anova $\chi^{2}=11.29, P=$ 0.0035 for $S$. oryzae, $\chi^{2}=8.74, P=0.0126$ ) (Fig. $2 \mathrm{E}, \mathrm{F}$ ). When $20 \mathrm{~S}$. oryzae and $80 \mathrm{~T}$. confusum adults were released, $S$. oryzae responded similarly to the traps (KW Anova, $\chi^{2}=1.28, P=0.5256$ ) (Fig. $2 \mathrm{G}$ ). In contrast, significantly more $T$. confusum adults were found in the traps with $1 \mathrm{~g}$ of the attractant compared to the other traps (KW Anova, $\chi^{2}=8.65, P=0.0132$ ) (Fig. $2 \mathrm{H}$ ). As above, significantly more adults of $T$. confusum were caught in traps than of $S$. oryzae $\left(\chi^{2}=22.51, d f=1, P<0.0001\right.$, for combined release, $\chi^{2}=22.77, d f=1, P<0.0001$ for separate release).

\section{Experiment 3 (Fig. 3A-F)}

When the ratio of numbers of the two species introduced into the arena was similar $(50: 50)$, the numbers of $S$. oryzae caught in the traps differed significantly (KW Anova $\chi^{2}=11.76, P=0.0028$ ). Significantly more adults were caught in the two traps that contained the contaminated filter papers compared to control traps (Fig. 3A). No significant differences were noted among traps for $T$. confusum (KW Anova $\chi^{2}=0.11, P=0.9478$ ) (Fig. 3B). For the $S$. oryzae : T. confusum release ratio of $80: 20$, the results were the same for T. confusum (KW Anova, $\chi^{2}$ $=1.36, P=0.5064$ ) (Fig. 3D). However, for $S$. oryzae significantly more adults were caught in the traps that contained the most contaminated filter paper (exposed to
50 individuals), than in the other two traps (KW Anova, $\chi^{2}=11.60, P=0.0030$ ) (Fig. 3C). Moreover, more $S$. oryzae adults were caught in the traps that contained the less contaminated filter paper (exposed to 5 individuals) than in control traps. The $20: 80(S$. oryzae : $T$. confusum) release ratio was the only case where $T$. confusum indicated a specific behavioural trend (KW Anova, $\left.\chi^{2}=7.23, P=0.0269\right)$. In this test, significantly more $T$. confusum adults were found in control traps compared to those containing the most contaminated filter papers (Fig. 3 F). For $S$. oryzae, significantly more adults were noted in traps containing the most contaminated filter paper (Fig. 3E). In experiment 3 no $S$. oryzae adults were found in control traps.

\section{Experiment 4 (Fig. 4A-B)}

Significantly different numbers of $S$. oryzae were caught to the traps (KW Anova, $\chi^{2}=12.95, P=0.0015$ ). Approximately $25 \%$ of the adults were found in the trap that contained the damaged seeds, and $<5.5 \%$ in the other traps (Fig. 4A). No significant differences were recorded among traps for $T$. confusum (KW Anova, $\chi^{2}=0.26, P=$ 0.8753) (Fig. 4B1), although significantly more adults of this species were found in traps than of $S$. oryzae $\left(\chi^{2}=\right.$ 22.64, $d f=1, P<0.0001)$.

\section{Experiment 5 (Fig. 4C-D)}

Significant differences were noted among traps for $S$. oryzae (KW Anova, $\left.\chi^{2}=12.32, P=0.0021\right)$ but not for $T$. confusum (KW Anova, $\chi^{2}=4.78, P=0.0915$ ) (Fig. 4C, D). Significantly more $S$. oryzae adults were caught in the traps that had damaged seeds, with or without oil, compared to control traps. Significantly more adults of T. con-
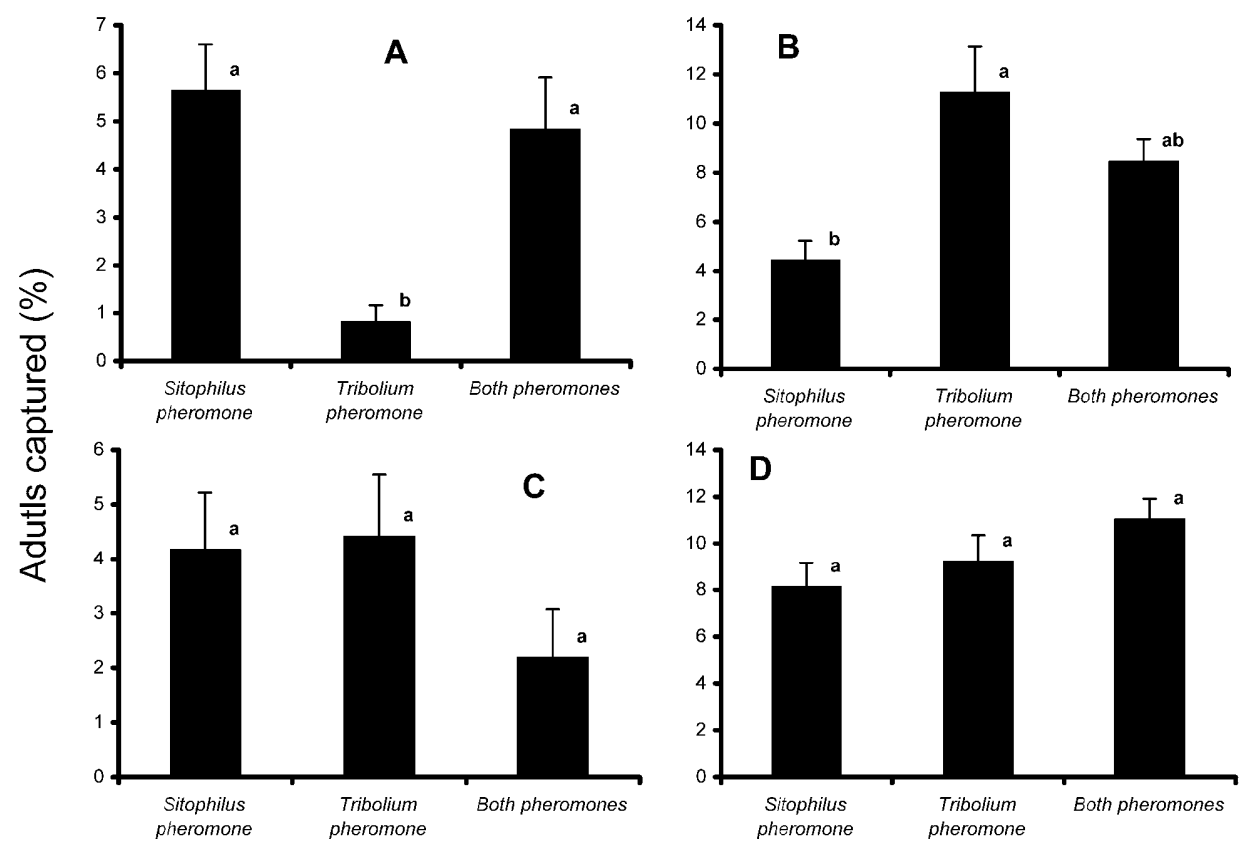

Fig. 1. Adults captured $( \pm \mathrm{SE})$ in traps containing pheromones. Adults introduced into the arena: A - 100 S. oryzae; B - $100 T$. confusum; C - captures of $S$. oryzae when $50 \mathrm{~S}$. oryzae $+50 \mathrm{~T}$. confusum adults were introduced; D - captures of T. confusum when $50 \mathrm{~S}$. oryzae $+50 \mathrm{~T}$. confusum adults were introduced (in each experiment, means followed by the same letter are not significantly different; Tukey's multiple comparison test at $P=0.05$ ). 

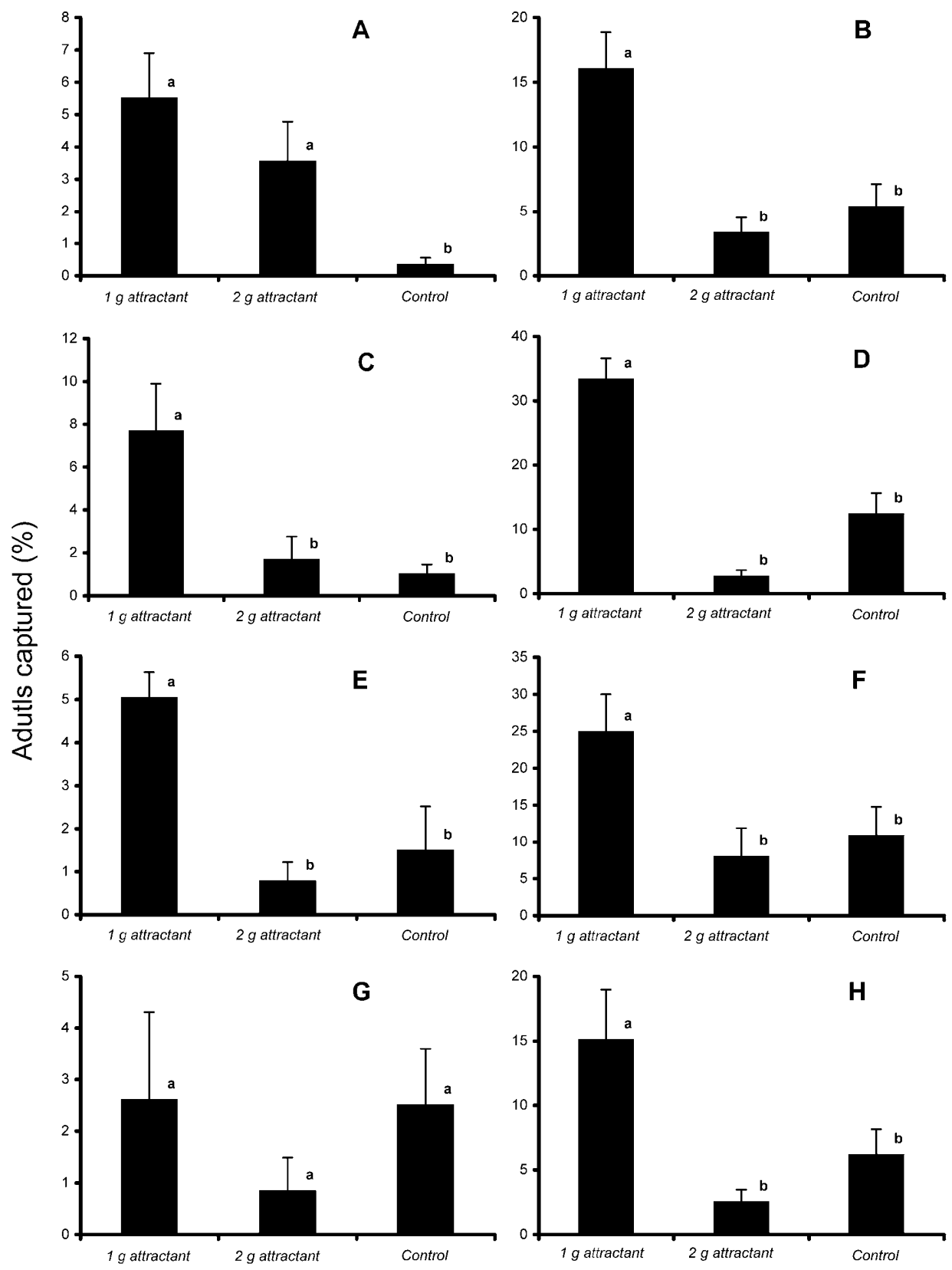

Fig. 2. Adults captured $( \pm \mathrm{SE})$ in traps containing multi-attractant. Adults introduced into the arena: A -100 S. oryzae; B $-100 T$. confusum; C - captures of $S$. oryzae when $50 \mathrm{~S}$. oryzae $+50 \mathrm{~T}$. confusum adults were introduced; D - captures of T. confusum when $50 \mathrm{~S}$. oryzae $+50 \mathrm{~T}$. confusum adults were introduced; E - captures of $S$. oryzae when $80 \mathrm{~S}$. oryzae $+20 \mathrm{~T}$. confusum adults were introduced; F - captures of $T$. confusum when $80 \mathrm{~S}$. oryzae $+20 \mathrm{~T}$. confusum adults were introduced; $\mathrm{G}-$ captures of $S$. oryzae when $20 \mathrm{~S}$. oryzae $+80 \mathrm{~T}$. confusum adults were introduced; $\mathrm{H}$ - captures of T. confusum when $20 \mathrm{~S}$. oryzae $+80 \mathrm{~T}$. confusum adults were introduced (in each experiment, means followed by the same letter are not significantly different; Tukey's multiple comparison test at $P=0.05)$.

fusum were found in the traps than of $S$. oryzae $\left(\chi^{2}=\right.$ 24.25, $P<0.0001)$.

\section{Experiment 6 (Fig. 4E-F)}

Significant differences were noted among traps for $S$. oryzae (KW Anova, $\chi^{2}=11.81, P=0.0027$ ). Approximately $25 \%$ of the $S$. oryzae adults released were found in the trap that contained live individuals. The presence of dead adults in the trap did not affect the number caught (Fig. 4E). No significant differences were noted among traps for $T$. confusum (Fig. 4F). As in the previous tests, significantly more adults of $T$. confusum were caught than of $S$. oryzae $\left(\chi^{2}=26.03, P<0.0001\right)$.

\section{DISCUSSION}

The potential of using a multi-attractive source, which is capable of multi-species detection in storage facilities, has appealed many researchers over recent years (Dowdy \& Mullen, 1998; Cox \& Collins, 2002; Athanassiou et al., 2003; Collins et al., 2004). The development of such an 

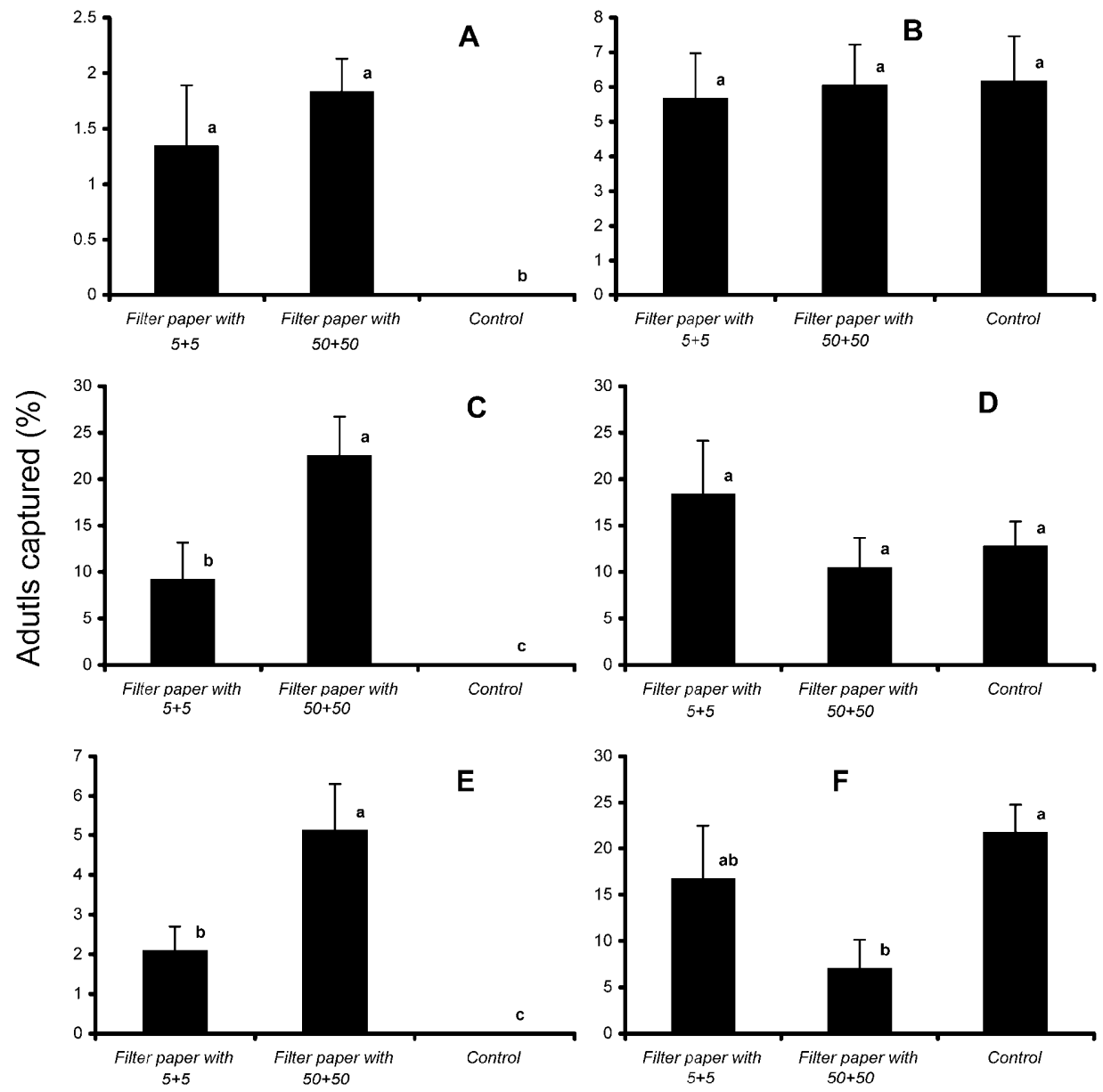

Fig. 3. Adults captured $( \pm \mathrm{SE})$ in traps containing filter papers. Adults introduced into the arena: A - captures of $S$. oryzae when $50 \mathrm{~S}$. oryzae $+50 \mathrm{~T}$. confusum adults were introduced; B - captures of T. confusum when $50 \mathrm{~S}$. oryzae +50 T. confusum adults were introduced; C - captures of S. oryzae when $80 \mathrm{~S}$. oryzae $+20 \mathrm{~T}$. confusum adults were introduced; D - captures of T. confusum when $80 \mathrm{~S}$. oryzae $+20 \mathrm{~T}$. confusum adults were introduced; E - captures of S. oryzae when $20 \mathrm{~S}$. oryzae $+80 \mathrm{~T}$. confusum adults were introduced; $\mathrm{F}$ - captures of $T$. confusum when $20 \mathrm{~S}$. oryzae $+80 \mathrm{~T}$. confusum adults were introduced (in each experiment, means followed by the same letter are not significantly different; Tukey's multiple comparison test at $P=0.05$ ).

attractant is an obvious answer to the problem of cross interactions among species in trapping performance. Furthermore, this subject is of great practical importance, because trap users may not want to use an attractant (such as a pheromone) that must be changed each time the species' predominance is altered, or use separate traps. Dowdy \& Mullen (1998) in semi-field tests using the same trap type as in the present study, with two pheromones in the same trap, found that the effectiveness of the trap was not affected when adults of Tribolium castaneum (Herbst), Rhyzopertha dominica (F.) and Trogoderma variabile (Ballion) were released in pairs. Similarly, Collins et al. (2004) used non-pheromonal attractants sources for the detection of Oryzaephilus surinamensis (L.), Sitophilus granarius (L.) and Cryptolestes ferrugineus (Stephens) and showed that the development of a multi-species lure is feasible. However, in laboratory experiments using perforated probe traps, Fargo et al. (1994) reported that the addition of pheromone did not increase captures of adult $S$. oryzae. In our case it is likely that adults responded more vigorously to traps that contained their pheromones shortly after their introduction, but following "saturation" the refuge-seeking behaviour occurred independently of the chemical stimuli. In contrast, the simultaneous presence of two species in the arena modified their response. According to the results of our study, the aggregation pheromones of both $S$. oryzae and $T$. confusum can be used simultaneously in the same trapping device, since each species is attracted by its own pheromone regardless of the presence or absence of the pheromone of the other species. However, T. confusum adults responded more to traps baited only with the pheromone of this species, but not significantly less than to traps that contained both pheromones.

Several plant-derived volatiles have affect in storedproduct beetle behaviour (Phillips et al., 1993; Landolt \& Phillips, 1997; Bashir et al., 2001; Athanassiou et al., 2003; Collins et al., 2004) such as carob extracts, for instance, used in a multi-species lure (Collins \& Chambers, 2003; Collins et al., 2004). In our tests, S. oryzae on its own exhibited a strong preference for the attractant lure, at both $1 \mathrm{~g}$ and $2 \mathrm{~g}$ concentrations, suggesting that this source is attractive for this species. On the other hand, in the case of $T$. confusum, only the $1 \mathrm{~g}$ level 

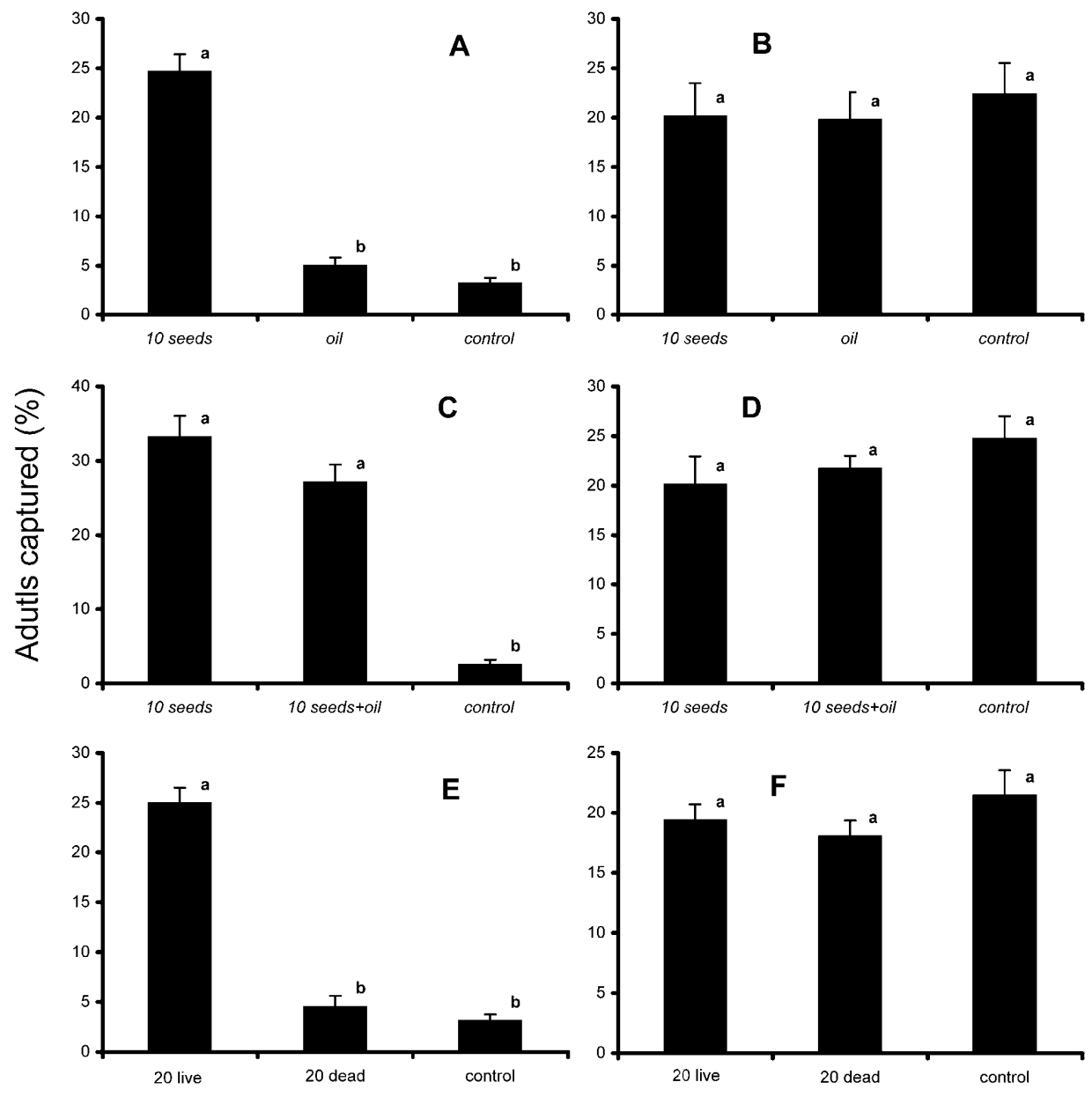

Fig. 4. Adults captured ( $\pm \mathrm{SE}$ ) in traps containing damaged seeds, oil, live and dead adults. Adults introduced into the arena: A $100 \mathrm{~S}$. oryzae; B - $100 \mathrm{~T}$. confusum; C - $100 \mathrm{~S}$. oryzae; D - 100 T. confusum; E - $100 \mathrm{~S}$. oryzae; F - $100 \mathrm{~T}$. confusum (in each experiment, means followed by the same letter are not significantly different; Tukey's multiple comparison test at $P=0.05$ ).

attracted beetles; this fact may indicate that the higher loading level of the attractant $(2 \mathrm{~g})$ acts as a repellent for this species. This trend was also evident when $S$. oryzae and $T$. confusum were released together into the arena at ratios of $50: 50$ and $80: 20$; in fact the level of $2 \mathrm{~g}$ repelled $S$. oryzae. In field tests using the same attractant in pitfall traps, Athanassiou et al. (2003), came to the same conclusion that even in cases where there is no repellent effect, nothing is gained by increasing the amount of attractant to $2 \mathrm{~g}$ for $S$. oryzae, O. surinamensis and $R$. dominica. Consequently $1 \mathrm{~g}$ is the recommended quantity of the attractant for improving the trapping efficiency and detection of stored-product beetle adults. However, at the $S$. oryzae : $T$. confusum release ratio of $20: 80$, only $T$. confusum responded to $1 \mathrm{~g}$ of the attractant, while $S$. oryzae was equally distributed among traps.

According to the results of Experiment 2, the behaviour of $S$. oryzae is highly affected by the presence and abundance of $T$. confusum, whereas that of the confused flour beetle to the given stimuli was the same at all densities and was unaffected by the presence of $S$. oryzae.

The response observed in Experiment 3, in which contaminated filter papers were used, is clearly attributable to the effect of the volatiles produced by the two species.
Traps that contained filter papers contaminated by large numbers of adults (50 individuals of each species) are highly attractive for $S$. oryzae adults and this behaviour is manifested regardless of the numbers of each species in the arena. In addition, even filter paper contaminated by a few adults (5 individuals of each species) clearly attracts adult weevils and no adults of $S$. oryzae were found in the control traps, which suggests that this weevil's volatiles are extremely attractive. Generally, a higher proportion of adult weevils was caught in the traps during these tests (in comparison with Experiments 1 and 2), which is an additional indication of a strong attraction. On the other hand, the presence of $T$. confusum volatiles absorbed on filter paper did not affect the capture of $S$. oryzae. In contrast to $S$. oryzae, $T$. confusum mostly was not attracted by contaminated filter paper. However, when T. confusum density was high control traps contained significantly higher numbers of adults compared to traps that contained filter papers contaminated by a high number of adults (50 individuals). Since both filter papers did not affect the number of $T$. confusum captured at the other release ratio, this may suggest that at a low density, $T$. confusum adults may choose traps that contained the least (or no) $S$. oryzae, as they are repelled by high numbers of $S$. oryzae. 
Though a very complex process, it is generally accepted that host selection by stored-product beetles differs between primary and secondary colonizers (Phillips et al., 1993; Landolt \& Phillips, 1997; Trematerra et al., 1999, 2000). For instance, Phillips et al. (1993) report that some grain-derived volatiles that attract $S$. oryzae adults repulse or had no effect on $T$. castaneum. In our tests, seeds damaged by $S$. oryzae were highly attractive to this species. This could be attributed to the host-seeking behaviour of Sitophilus spp.; adults move actively at random until they detect a spot suitable for infestation (Surtees, 1964; Plarre, 1996), then an aggregation pheromone is released that attracts other colonizers of the same species (Walgenbach et al., 1983; Walgenbach \& Burkholder, 1986; Landolt \& Phillips, 1997). Seeds damaged by other rice weevils and the presence of saliva or frass, may modify the emission of volatiles from specific parts of the seed, such as the germ or the kernel endosperm, which are highly attractive or act as an arrestant for adult $S$. oryzae (Trematerra et al., 1999). In addition, damaged seed are an easier food source for weevils. Thus, the presence of such seed in traps may provide both a phagostimulant and aggregation stimuli. In contrast, oil does not seem to attract $S$. oryzae. Also, the addition of oil to traps may make cleaning of the traps and identification of the insects more difficult (Collins \& Chambers, 2003). In Experiments 2 and 3,T. confusum captures were unaffected by oil or damaged seeds used. However, Trematerra et al. (2000) noted that kernels damaged by primary pests, especially $S$. oryzae, are generally preferred by the secondary pests $O$. surinamensis, $T$. castaneum and $T$. confusum, compared to artificially damaged or whole kernels. This is considered to be a part of the host seeking behaviour of the secondary granivores (Landolt \& Phillips, 1997).

The results were similar in Experiment 5, in which the presence of damaged seeds increased the response of $S$. oryzae to the traps, compared to the control. The addition of oil to the traps that contained the seeds did not increase captures. Thus, as noted for Experiment 4, nothing is gained by the addition of oil to the traps when monitoring for $S$. oryzae. As above, T. confusum was not attracted by these substances.

Trematerra et al. (1996), using similar bioassays, found that the presence of live $T$. castaneum adults made the traps more attractive to adults of the same species. This behaviour is attributed to the production of an aggregation pheromone by this beetle. The presence of dead $T$. castaneum specimens in the traps was repulsive to other insects of the same species, due possibly to the production of an alarm pheromone, before death. In our tests with $S$. oryzae (Experiment 6) only the first of the two aforementioned phenomena was observed; the presence of live weevils increased the capture of $S$. oryzae, but dead weevils did not affect the number caught. Like damaged seeds, the presence of live weevils is clearly attractive to other weevils. In contrast, the presence of dead or live $S$. oryzae adults had no effect on the response of $T$. confusum, indicating that the chemicals are species spe- cific and were not attractive to $T$. confusum, and probably other secondary species. However, according to Trematerra et al. (2000), live $S$. oryzae along with damaged kernels are attractive to $T$. confusum. In the case of $T$. castaneum, the augmentative effect of live individuals in traps is not consistent. A high number of adults results in the production of quinones or other repellent volatiles, like alarm pheromones, that suppress aggregation (Trematerra et al., 1996). Apparently, adults of S. oryzae behave differently, as far as volatile emission is concerned. Practically, traps that are not inspected very often may provide inaccurate results, given that the accumulation of captured individuals may over- or underestimate the actual presence of a given species in a given storage facility (Plarre, 1996; Collins \& Chambers, 2003; Collins et al., 2004).

From an ecological point of view, interactions among species sharing the same environment often cause insects to change their behaviour, which acts as a stabilizing factor that prevents them from becoming extinct; this may result in the formation of metapopulations, which are formed by locally developed populations that fluctuate independently (Hanski, 1999). In stored-product ecosystems a species is never alone and this fact should be taken into account when assessing trapping parameters by laboratory bioassays. In the light of our findings, at least in some cases, the simultaneous presence of $S$. oryzae and $T$. confusum results in a different behaviour than when a single species is present. Of these two species, S. oryzae was much more sensitive to the stimuli tested than $T$. confusum.

ACKNOWLEDGEMENTS. We are grateful to K. Mori (University of Tokyo, Japan), for supplying the $S$. oryzae pheromone, and E. Casagrande (Agrisense BCS, UK) for supplying the multi-attractant lure. This study was partially supported by the Cost STSM 842-960 and by the State Scholarships Foundation. We are also grateful to the anonymous referees for suggestions.

\section{REFERENCES}

Athanassiou C.G. \& Buchelos C.Th. 2001: Detection of storedwheat beetle species and estimation of population density using unbaited probe traps and grain trier samples. Entomol. Exp. Appl. 98: 67-78.

Athanassiou C.G., Kavallieratos N.G., Eliopoulos P.A., Palyvos N.E., Casagrade E. \& Buchelos C.Th. 2003: Evaluation of a multi-attractant on the capture of several stored-product beetle species. In Credland P.F., Armitage D.M., Bell C.H., Cogan P.M. \& Highley E. (eds): Proceedings of the 8th International Conference on Stored-Product Protection, York, 22-26 July 2002. CAB International, Wallingford, Oxon, pp. 252-257.

Bashir T., Birkinshaw L.A., Hall D.R. \& Hodges R.J. 2001: Host odours enhance the responses of adult Rhyzopertha dominica to male-produced aggregation pheromone. Entomol. Exp. Appl. 101: 273-280.

Collins L.E. \& Chambers J. 2003: The I-SPy Insect Indicator: an effective trap for the detection of insect pests in empty stores and on flat surfaces in the cereal and food trades. $J$. Stored Prod. Res. 39: 277-292. 
Collins L.E., Wakefield M.E., Chambers J. \& Cox P.D. 2004: Progress towards a multi-species lure: comparison of behavioural bioassay methods for multi-species attractants against three pests of stored-grain. J. Stored Prod. Res. 40: 341-353.

Cox P.D. \& Collins L.E. 2002: Factors affecting the behaviour of beetle pests in stored grain, with particular reference to the development of lures. J. Stored Prod. Res. 38: 95-115.

Cox P.D., PARIsh W.E. \& Ledson M. 1990: Factors affecting the refuge-seeking behavior of Cryptolestes ferrugineus (Stephens) (Coleoptera: Cucujidae). J. Stored Prod. Res. 26: 169-174.

Dowdy A.K. \& Mullen M.A. 1998: Multiple stored-product insect pheromone use in pitfall traps. J. Stored Prod. Res. 34: $75-80$.

Fargo W.S., Cuperus G.W., Bonjour E.L., Burkholder W.E., Clary B.L. \& PAYton M.E. 1994: Influence of probe trap type and attractants on the capture of four stored-grain Coleoptera. J. Stored Prod. Res. 30: 237-241.

Hagstrum D.W., Flinn P.W. \& Subramanyam Bh. 1998: Predicting insect density from probe trap catch in farm-stored wheat. J. Stored Prod. Res. 34: 251-262.

HANSKI I. 1999: Metapopulation Ecology. Oxford University Press, Oxford, 328 pp.

Landolt P.J. \& Phillips T.W. 1997: Host plant influences on sex pheromone behavior of phytophagous insects. Annu. Rev. Entomol. 42: 371-391.

Levinson H.Z., Levinson A., Ren Z. \& Mori K. 1990: Comparative olfactory perception of the aggregation pheromones of Sitophilus oryzae (L.), S. zeamais (Motsch.) and S. granarius (L.), as well as the stereoisomers of these pheromones. $J$. Appl. Entomol. 110: 203-213.

Likhayo P.W. \& Hodges R.J. 2000: Field monitoring Sitophilus zeamais and Sitophilus oryzae (Coleoptera: Curculionidae) using refuge and flight traps baited with synthetic pheromone and cracked wheat. J. Stored Prod. Res. 36: 341-353.

PhILLIPS T.W. 1997: Semiochemicals of stored-product insects: Research and applications. J. Stored Prod. Res. 33: 17-30.

Phillips T.W., Jiang X.L., Burkholder W.E., Phillips J.K. \& TRAN H.Q. 1993: Behavioural responses to food volatiles by two species of stored-product Coleoptera, Sitophilus oryzae (Curculionidae) and Tribolium castaneum (Tenebrionidae). $J$. Chem. Ecol. 19: 723-734.

PlarRe R. 1996: Three-dimentional distribution of Sitophilus granarius (L.) (Coleoptera: Curculionidae) in wheat influenced by the synthetic aggregation pheromone. J. Stored Prod. Res. 32: 275-283.
ReEs D.P. 1995: Coleoptera. In Subramanyam Bh. \& Hagstrum D.W. (eds): Integrated Management of Insects in Stored Products. Marcel Dekker, New York, pp. 3-11.

Sall J., Lehman A. \& Creighton L. 2001: JMP Start Statistics. A Guide to Statistics and Data Snalysis Using JMP and JMP IN Software. Duxbury Press, Belmont, $491 \mathrm{pp}$.

Siegel S. \& Castellan N.J.R. 1988: Nonparametric Statistics for the Behavioral Sciences. McGraw-Hill, New York, 399 pp.

Subramanyam Bh. \& Hagstrum D.W. 1995: In Subramanyam Bh. \& Hagstrum D.W. (eds): Integrated Management of Insects in Stored Products. Marcel Dekker, New York, pp. 142-188.

SuRTeEs G. 1964: Laboratory studies on the dispersion behaviour of adult beetles in grain VI. Three dimensional analysis of dispersion of five species in a uniform bulk. Bull. Entomol. Res. 55: 161-171.

Trematerra P., Fontana F. \& Mancini M. 1996: Effects of accumulate dead and live insects in trap on the capture of Tribolium castaneum (Herbst). Anz. Schädlingsk. Pflanzenschutz Umweltschutz 69: 3-9.

Trematerra P., Fontana F., Mancini M. \& Sciaretta A. 1999: Influence of intact and damaged cereal kernels on the behaviour of rice weevil, Sitophilus oryzae (L.) (Coleoptera: Curculionidae). J. Stored Prod. Res. 35: 265-276.

Trematerra P., Sciarreta A. \& Tamasi E. 2000: Behavioural responses of Oryzaephilus surinamensis, Tribolium castaneum and Tribolium confusum to naturally and artificially damaged durum wheat kernels. Entomol. Exp. Appl. 94: 195-200.

Walgenbach C.A. \& Burkholder W.E. 1986: Factors affecting the response of maize weevil, Sitophilus zeamais (Coleoptera: Tenebrionidae), to its aggregation pheromone. Environ. Entomol. 15: 733-738.

Walgendach C.A., Phillips J.K., Faustini D.L. \& Burkholder W.E. 1983: Male-produced aggregation pheromone of the maize weevil, Sitophilus zeamais, and interspecific attraction between three Sitophilus species. J. Chem. Ecol. 9: 831-841.

Walgenbach C.A., Burkholder W.E., Curtis M.J. \& Khan Z.A. 1987: Laboratory trapping studies with Sitophilus zeamais (Coleoptera: Curculionidae). J. Econ. Entomol. 80: 763-767.

WILKIN D.R. 1990: Detection of insects in bulk grain. J. Kansas Entomol. Soc. 63: 554-558.

Received April 18, 2005; revised and accepted November 21, 2005 